\title{
Acrofacial dysostosis, Palagonia type
}

INSERM

\section{Source}

INSERM. (1999). Orphanet: an online rare disease and orphan drug data base. Acrofacial dysostosis, Palagonia type. ORPHA:1787

Acrofacial dysostosis, Palagonia type is a very rare form of acrofacial dysostosis, reported in four members of a family from the Sicilian village of Palagonia, characterized by normal intelligence, shortness of stature, and mild acrofacial dysostosis (malar hypoplasia, microg nathia and webbing of digits with shortening of the fourth metacarpals) associated with oligodontia, normal or high arched palate, aplasia cutis verticis with pili torti, mild cutaneous syndactyly of digits 2-5, webbing of digits and shortening of the fourth metacarpals, and unilateral cleft lip. Features are similar to those seen in Zlotogora-Ogur syndrome (see this term), although the latter shows no sign of acrofacial dysostosis. There have been no further reports in the literature since 1997. 